\title{
Seizure Freedom in Temporal Plus Epilepsy Surgery Following Stereo- Electroencephalography
}

\author{
Juan S. Bottan, Ana Suller Marti, Andrew G. Parrent, Keith W. MacDougall, \\ Richard S. McLachlan, Jorge G. Burneo, David A. Steven
}

ABSTRACT: Background: "Temporal plus" epilepsy (TPE) is a term that is used when the epileptogenic zone (EZ) extends beyond the boundaries of the temporal lobe. Stereotactic electroencephalography (SEEG) has been essential to identify additional EZs in adjacent structures that might be part of the temporal lobe/limbic network. Objective: We present a small case series of temporal plus cases successfully identified by SEEG who were seizure-free after resective surgery. Methods: We conducted a retrospective analysis of 156 patients who underwent SEEG in 5 years. Six cases had TPE and underwent anterior temporal lobectomy (ATL) with additional extra-temporal resections. Results: Five cases had a focus on the right hemisphere and one on the left. Three cases were non-lesional and three were lesional. Mean follow-up time since surgery was 2.9 years (SD \pm 1.8 ). Three patients had subdural electrodes investigation prior or in addition to SEEG. All patients underwent standard ATL and additional extra-temporal resections during the same procedure or at a later date. All patients were seizure-free at their last follow-up appointment (Engel Ia $=3$; Engel $\mathrm{Ib}=2$; Engel $\mathrm{Ic}=1$ ). Pathology was nonspecific/gliosis for all six cases. Conclusion: TPE might explain some of the failures in temporal lobe epilepsy surgery. We present a small case series of six patients in whom SEEG successfully identified this phenomenon and surgery proved effective.

RÉSUMÉ: Absence de crise convulsive en lien avec une résection chirurgicale pour l'épilepsie temporale plus à la suite d'un examen de stéréoencéphalographie. Contexte: «Épilepsie temporale plus» (temporal plus epilepsy) est un terme qu'on utilise lorsque la zone épileptogène d'un patient va au-delà des frontières du lobe temporal. La stéréo-encéphalographie (SEEG) s'est quant à elle révélée essentielle pour identifier, dans des structures adjacentes, les zones épileptogènes additionnelles qui pourraient faire partie du lobe temporal ou du réseau limbique. Objectif: Nous voulons présenter ici une petite série de cas d'épilepsie temporale plus identifiés avec succès par SEEG. Leur particularité était d'être exempts de crise convulsive à la suite d'une résection chirurgicale. Méthodes: Nous avons ainsi effectué une analyse rétrospective de 156 patients soumis à une SEEG au cours d'une période de 5 ans. Au total, 6 patients étaient atteints d'épilepsie temporale plus et ont bénéficié d'une lobectomie temporale antérieure (LTA) ainsi que de résections extra-temporales additionnelles. Résultats: Sur ces 6 patients, 5 étaient atteints dans l'hémisphère droit, l'autre étant atteint dans l'hémisphère gauche ; 3 d'entre eux ne donnaient à voir aucune lésion alors que 3 autres en donnaient à voir. La période moyenne de suivi après une chirurgie s'est établie à 2,9 ans (écart-type $\pm 1,8$ ). Fait à noter, 3 patients ont par ailleurs fait l'objet d'une évaluation par électrodes sous-durales avant une SEEG ou en plus d'une SEEG. Tous les patients ont été soumis à une LTA standard ainsi qu'à des résections extra-temporales additionnelles au cours de la même procédure ou à une date ultérieure. Une absence de crise convulsive a également été notée chez tous les patients au moment de leur dernier suivi (échelle d'Engel Ia $=3 ; \mathrm{Ib}=2 ; \mathrm{Ic}=1$ ). Enfin, cette pathologie de nature épileptique s'est avérée constante tant en ce qui concerne des changements réactifs non spécifiques aux cellules gliales que d'autres changements non spécifiques, et ce, pour ces 6 patients. Conclusion: Il se pourrait que l'épilepsie temporale plus explique quelques-uns des échecs consécutifs à une intervention chirurgicale visant à traiter l'épilepsie du lobe temporal. Nous avons du coup présenté une petite série de cas (6 patients) pour lesquels la SEEG a pu identifier avec succès ce phénomène et pour lesquels la résection s'est avérée efficace.

Keywords: Temporal lobe epilepsy, Temporal lobectomy, Insula, Epilepsy surgery, Stereolectroencephalography, Temporal plus epilepsy

doi:10.1017/cjn.2020.26

Can J Neurol Sci. 2020; 47: 374-381

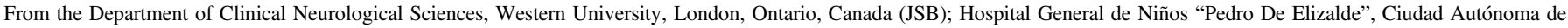

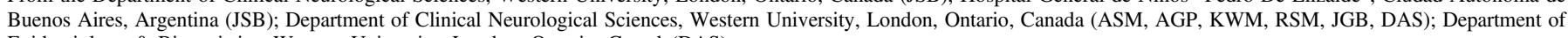
Epidemiology \& Biostatistics, Western University, London, Ontario, Canada(DAS)

Received April 24, 2019. Final Revisions Submitted January 30, 2020. Date of Acceptance February 1, 2020.

Correspondence to: David A. Steven, Department of Clinical Neurological Sciences, Western University, London, Ontario, Canada. Email: david.steven@uwo.ca 


\section{INTRODUCTION}

"Temporal plus" epilepsy (TPE) has been described as a condition in which the epileptogenic zone (EZ) extends beyond the anatomic boundaries of the temporal lobe. ${ }^{1,2}$ It can be distinguished from dual pathology, where two independent epileptogenic foci exist. In TPE, the additional focus is closely related functionally and anatomically to the temporal lobe. ${ }^{3}$ Recently, better characterization of TPE has helped to explain some failures in temporal lobectomies. ${ }^{4,5}$ Stereotactic electroencephalography (SEEG) has been essential to the identification of additional EZs that might be part of the temporal lobe/limbic network, but located in adjacent structures, such as orbitofrontal cortex, frontal or parietal opercula, temporoparieto-occipital junction, or the insula. It has been argued that resection of these structures, in addition to the temporal lobectomy, might improve surgical outcomes. ${ }^{6}$ We present a small series of TPE cases, who underwent surgical resections following SEEG investigation and achieved seizure freedom.

\section{Material AND Methods}

We retrospectively reviewed 156 patients who underwent SEEG between June 2013 and December 2018, of whom 88 cases had subsequent resective surgery. Six cases were identified as TPE. We considered TPE if the case fulfilled the following criteria: (a) patients had electroclinical evidence of temporal lobe epilepsy (TLE), (b) normal magnetic resonance imaging (MRI) or radiological signs of mesial temporal sclerosis (MTS), and (c) intracranial EEG (electroencephalography) confirmation of two foci with simultaneous seizure onset or two distinct foci generating independent seizures (one focus located within the resectable temporal lobe and the second one in the adjacent structures: orbitofrontal cortex, opercular cortex, insular cortex, or temporo-parieto-occipital junction). ${ }^{1}$ Seizure types and semiology classification were based on the International League Against Epilepsy (ILAE) 2017 operational classification of seizure types. 7,8

In all cases, preoperative evaluations included: MRI of the brain (epilepsy protocol), prolonged scalp video-EEG recordings (VEEG), neuropsychological evaluation, and intracranial investigation via SEEG. Two patients had 18-fluorodeoxyglucose positron emission tomography (18FDG-PET). In addition, some cases were previously implanted with subdural electrodes. As a standard practice in our center, the patients were followed up at 6 weeks, 6 months, and then yearly. Medical records, pathology, and operative reports were reviewed retrospectively. To adequately identify the resected area, careful comparison between reports, preoperative images, and postoperative images were performed. Surgical techniques for anterior temporal lobectomy (ATL), subdural strips implantation, and depth electrodes implantation were performed following standard techniques described in earlier publications..$^{9-11}$ The present study was approved by Western University's ethics committee.

\section{RESULTS}

Of the 88 patients that had surgery following SEEG investigation, 6 cases were identified as TPE, representing $6.8 \%$ of all surgical cases. Five cases were right-sided TPE and one case was left-sided. Median age at the time of the surgery was 37 years $(\mathrm{IQR}=31-42)$ and median duration of epilepsy was 16 years $(\mathrm{IQR}=12-41)$. Three cases were non-lesional and three were lesional. Mean follow-up time after surgery was 2.7 years $(\mathrm{SD} \pm 1.7)$. Noninvasive electroclinical findings, neuropsychology, and neuroimaging are shown in Table 1 . Three patients had subdural

Table 1: Noninvasive studies: clinical features (seizure type, onset, and most prominent features), interictal and ictal EEG findings, neuropsychological testing, and MRI

\begin{tabular}{|c|c|c|c|c|c|c|c|}
\hline Case & $\begin{array}{c}\text { Age } \\
\text { (years) }\end{array}$ & Seizure semiology & Interictal EEG & Ictal EEG & DH & Neuropsychology & MRI \\
\hline 1 & 31.6 & $\begin{array}{l}\text { Type1: Hypermotor } \\
\text { Type2: BA }\end{array}$ & $\begin{array}{l}\text { Independent bifrontal and } \\
\text { bitemporal spikes. R } \\
\text { frontal theta }\end{array}$ & $\begin{array}{l}\mathrm{R} \text { frontal and temporal } \\
\text { polyspikes }\end{array}$ & $\mathrm{L}$ & $\begin{array}{l}\text { Bilateral frontal and } \\
\text { temporal dysfunction }\end{array}$ & Normal \\
\hline 2 & 33.8 & $\begin{array}{l}\text { Reflex epilepsy. BA, OA, L head } \\
\text { and eye deviation }\end{array}$ & Bitemporal spikes & $\begin{array}{l}\mathrm{R} \text { temporal onset with } \\
\text { suprasylvian extension }\end{array}$ & $\mathrm{L}$ & Normal & $\begin{array}{l}\text { Normal + R hippocampal } \\
\text { sulcus remnant cysts }\end{array}$ \\
\hline 3 & 27.6 & $\begin{array}{l}\text { Aura: Nausea and metallic taste, } \\
\text { spitting, drooling, L versive, L } \\
\text { dystonic posturing. }\end{array}$ & $\begin{array}{l}\mathrm{R} \text { posterior temporal } \\
\text { spikes }\end{array}$ & R hemispheric activity & $\mathrm{L}$ & Normal & Normal \\
\hline 4 & 39.8 & $\begin{array}{l}\text { Aura: fear/anxiety, R upper limb } \\
\text { sensation, BA, R versive, clonic } \\
\text { jerking L UE. }\end{array}$ & $\begin{array}{l}\text { Sleep-activated } \\
\text { independent bilateral } \\
\text { temporal spikes } \mathrm{L}>\mathrm{R} \text {. } \\
\text { Bitemporal slowing }\end{array}$ & $\mathrm{L}$ posterior temporal onset & $\mathrm{L}$ & $\begin{array}{l}\text { Blateral mesial temporal } \\
\text { dysfunction. Wada test: } \\
\text { bilateral memory deficit. }\end{array}$ & Bilateral MTS \\
\hline 5 & 46.5 & $\begin{array}{l}\text { Type1: BTC } \\
\text { Type2: BA, R hand automatisms }\end{array}$ & $\mathrm{R}$ temporal spikes & $\begin{array}{l}\mathrm{R} \text { frontal and temporal } \\
\text { onset }\end{array}$ & $\mathrm{L}$ & $\begin{array}{l}\mathrm{R} \text { frontal and temporal } \\
\text { neocortical dysfunction. }\end{array}$ & Ventriculomegaly \\
\hline 6 & 40.4 & $\begin{array}{l}\text { BA, bimanual automatisms, } \\
\text { bilateral jerking UE. }\end{array}$ & $\mathrm{R}$ frontotemporal spikes & No activity recorded & $\mathrm{L}$ & Normal & Hemosiderosis $\mathrm{R}$ insula. \\
\hline
\end{tabular}

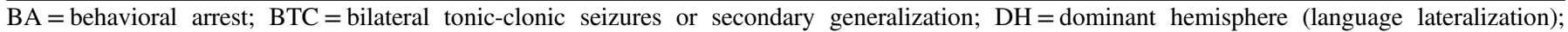

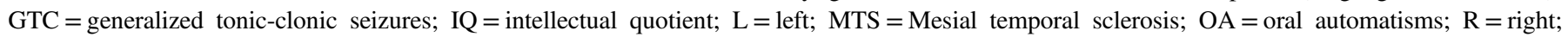
$\mathrm{UE}=$ upper extremity.

Seizure classification according to ILAE 2017. 


\section{Table 2: Summary of invasive studies and surgical resections}

\begin{tabular}{|c|c|c|c|c|c|}
\hline Case & Interictal SEEG & Ictal SEEG & $\begin{array}{l}\text { Total resective } \\
\text { surgeries }(n)\end{array}$ & Total resection & Engel class \\
\hline 1 & Spikes in $\mathrm{R} \mathrm{Am}$ & $\begin{array}{l}\text { Polyspikes } \mathrm{R} \text { mesial orbitofrontal area. } \\
\text { High-amplitude spikes in } \mathrm{R} \text { mesial } \\
\text { temporal }\end{array}$ & 2 & R ATL + R orbitofrontal corticectomy & $\mathrm{Ib}$ \\
\hline 2 & Spikes in $\mathrm{R}$ temporal & $\begin{array}{l}\text { Sequential high-amplitude spikes in } \mathrm{R} \\
\text { insula, Am, and } \mathrm{H} \text {. Delta activity in } \mathrm{R} \\
\text { anterior insula, } \mathrm{H} \text {, and } \mathrm{Am} \text {. }\end{array}$ & 1 & $\begin{array}{l}\mathrm{R} \mathrm{ATL}+\mathrm{R} \text { anterior/inferior insular } \\
\text { resection }\end{array}$ & Ia \\
\hline 3 & Spikes in $\mathrm{R}$ mesial temporal & $\begin{array}{l}\text { Polyspikes R PH. LVFA AH, and PH. Quick } \\
\text { extension to R anterior insula or simultaneous } \\
\text { onset in R AH and R posterior insula }\end{array}$ & 1 & $\mathrm{R}$ ATL $+\mathrm{R}$ inferior insular resection & $\mathrm{Ia}$ \\
\hline 4 & Spikes in L PH & Medium voltage spikes in L insula & 2 & $\begin{array}{l}\mathrm{L} \text { ATL + extended } \mathrm{PH} \text { resection }+\mathrm{L} \\
\text { anterior insular resection }\end{array}$ & $\mathrm{Ib}$ \\
\hline 5 & Spikes in $\mathrm{R} \mathrm{H}$, Am, and temporal pole & $\begin{array}{l}\text { LVFA R Am and H. LVFA R orbitofrontal } \\
\text { spread to temporal convexity to mesial } \\
\text { temporal. }\end{array}$ & 1 & R ATL + R orbitofrontal corticectomy & $\mathrm{Ia}$ \\
\hline 6 & Spikes $\mathrm{R}$ insual & LVFA in $\mathrm{R}$ insula & 3 & $\begin{array}{l}\text { Lesionesctomy + R ATL + R insular } \\
\text { resection }\end{array}$ & Ic \\
\hline
\end{tabular}

Am = amygdala; $\mathrm{AH}=$ anterior hippocampus; $\mathrm{ATL}=$ Anterior temporal lobectomy; Engel class = Engel classification; $\mathrm{H}=$ hippocampus; $\mathrm{L}=$ left; LVFA = low-voltage fast activity; $\mathrm{PH}=$ posterior hippocampus; $\mathrm{R}=$ right; $\mathrm{SEEG}=$ stereo-encephalography.

(A)

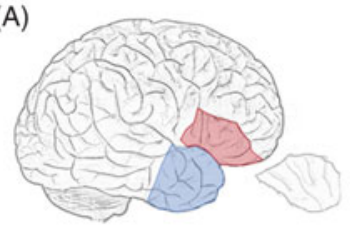

(D)

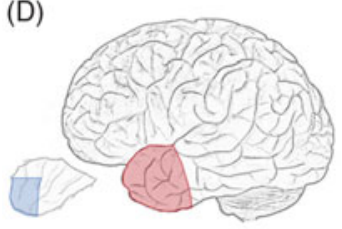

(B)

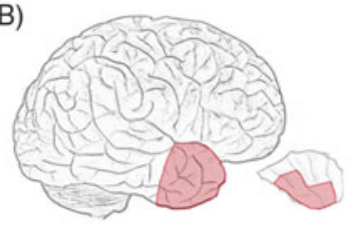

(E)

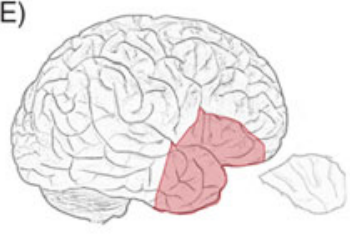

(C)

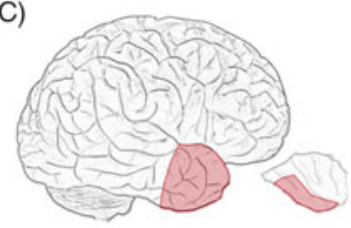

(F)

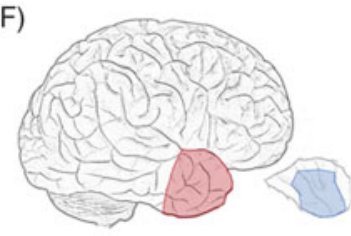

Tissue resected on $1^{\text {st }}$ surgery

Tissue resected on $2^{\text {nd }}$ surgery

Figure 1: Illustration of resected tissue for each case in each surgery. (A) Case 1: Right anterior temporal lobectomy + orbitofrontal resection. (B) Case 2: Right anterior temporal lobectomy + posterior inferior insular resection. (C) Case 3: Right anterior temporal lobectomy + inferior insular resection. (D) Case 4: Left anterior temporal lobectomy + anterior inferior insular resection. (E) Case 5: Right anterior temporal lobectomy + orbitofrontal resection. $(F)$ Case 6: Right anterior temporal lobectomy + subtotal insular resection.

electrodes investigation prior or in addition to SEEG. All patients underwent standard ATL and additional resections during the same procedure or subsequent surgery. All patients were seizure-free at their last follow-up appointment. Three patients were classified as Engel Ia, two patients experienced postoperative auras (Engel Ib), and one patient had scarce postoperative seizures that remitted spontaneously, being seizure-free for most of the follow-up time (Engel Ic). Table 2 summarizes invasive findings and surgical resections with postoperative outcomes. Pathology was consistent with either gliosis and or nonspecific changes in all cases for all resected tissue submitted for histopathology. Illustrations for each resection are shown in Figure 1A-F. A brief description of the six cases is shown below:

Case 1: Thirty-one-year-old, right-hand dominant male. He began having seizures at the age of 3 years. At the time of surgical evaluation, he presented two types of seizures. First type was nocturnal focal aware seizures with prominent type-1 hypermotor features. ${ }^{12}$ Second type was less frequent, consisted of daytime focal unaware seizures with behavioral arrest and blurry vision that occasionally progressed to bilateral tonic-clonic (BTC) seizures. Neuropsychological evaluation showed left 


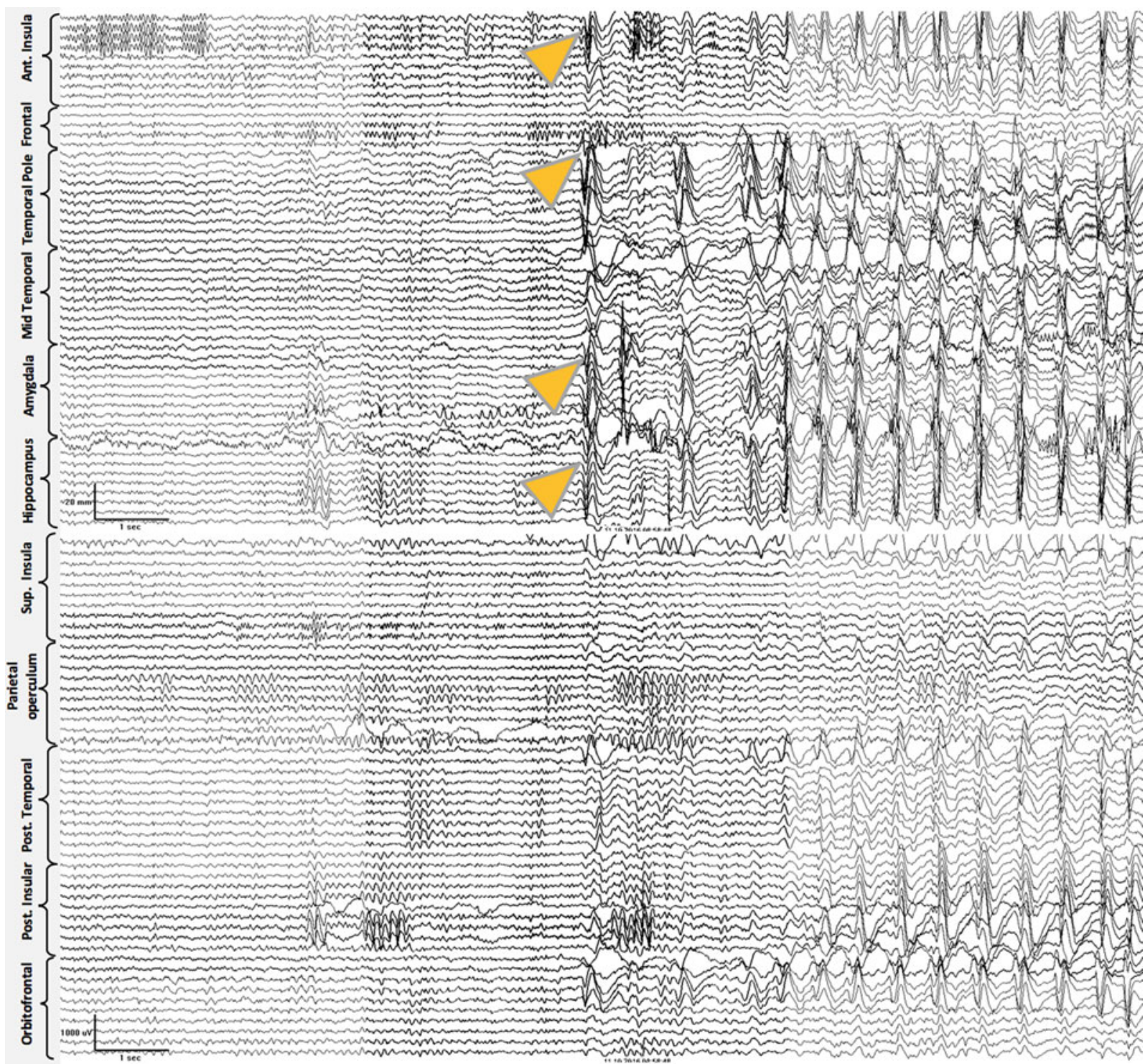

Figure 2: Case 2. Ictal Stereo-EEG (Referential montage): all the seizures recorded were electrographically stereotyped and preceding the clinical onset. Simultaneous onset with high voltage spikes over right anterior insula, amygdala, and anterior hippocampus (onset shown with yellow arrowheads), followed by sequential spikes spreading to adjacent electrodes. Subsequently, ictal activity involved nearly all electrodes and ended abruptly (ending not included in the image).

language dominance and non-lateralizing frontotemporal dysfunction. MRI was normal. Scalp EEG revealed bilateral frontotemporal spikes and seizures with activity more prominent in the right frontal lobe. The patient underwent invasive EEG recording in the form of subdural strips covering bifrontal and bitemporal regions on two occasions. On the first occasion, the patient had no seizures while admitted to the epilepsy unit. On the second occasion, orbitofrontal spikes were found, and supplementary strips in the orbitofrontal area were implanted. Four seizures were captured from the right orbitofrontal area and one from the right mesial temporal region. A staged resection was proposed: first, the orbitofrontal region was partially resected, but the patient continued having seizures with the same frequency and semiology. SEEG was then performed covering the right temporal and orbitofrontal regions: three independent seizures originating in the right mesial temporal region and in the ipsilateral orbitofrontal cortex, adjacent to the previous resection, were found. The patient underwent a right-sided ATL with additional orbitofrontal resection (Figure 1A). He has been seizure-free with persistence of occasional auras with a follow-up time of 2.4 years.

Case 2: Thirty-two-year-old, right-hand dominant male with a history of reflex epilepsy triggered by eating for 5 years. The patient sustained somatosensory seizures with oral automatisms, left head and eye deviation, and postictal right-hand nose wiping. Neuropsychological testing was normal with left language lateralization. MRI revealed hippocampal sulcus remnant cysts on the right. These were considered incidental findings with no abnormal changes in hippocampal volume or signal. PET scan was normal. Scalp EEG showed right temporal seizures extending to the suprasylvian region. The 


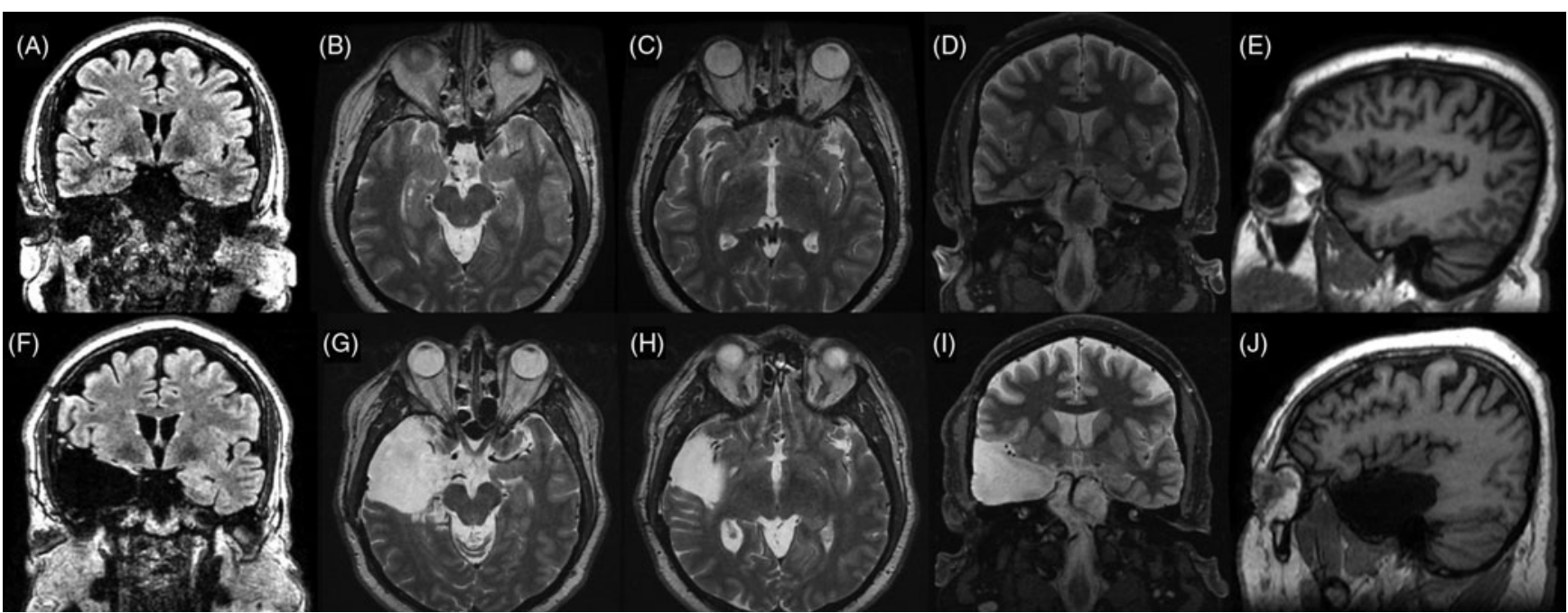

Figure 3. Preoperative (superior line images A-D) and postoperative (inferior line images E-H) MRI images for Case 2. (A) Preoperative FLAIR coronal image at the level of the anterior hippocampus. (B) T2-weighted coronal image at the level of anterior hippocampus and posterior section of amygdala. (C) T2-weighted axial image at the level of the amygdala-hippocampus complex. (D) T2-weighted axial image at the level of the insula. (E) T1-weighted sagittal image at the level of the right temporal lobe and insula. (F) Postoperative comparison to image A. (G) Postoperative comparison to image B. (H) Postoperative comparison to image C. (I) Postoperative comparison to image D. (J) Postoperative comparison to image E showing temporal lobectomy and inferior insular resection.
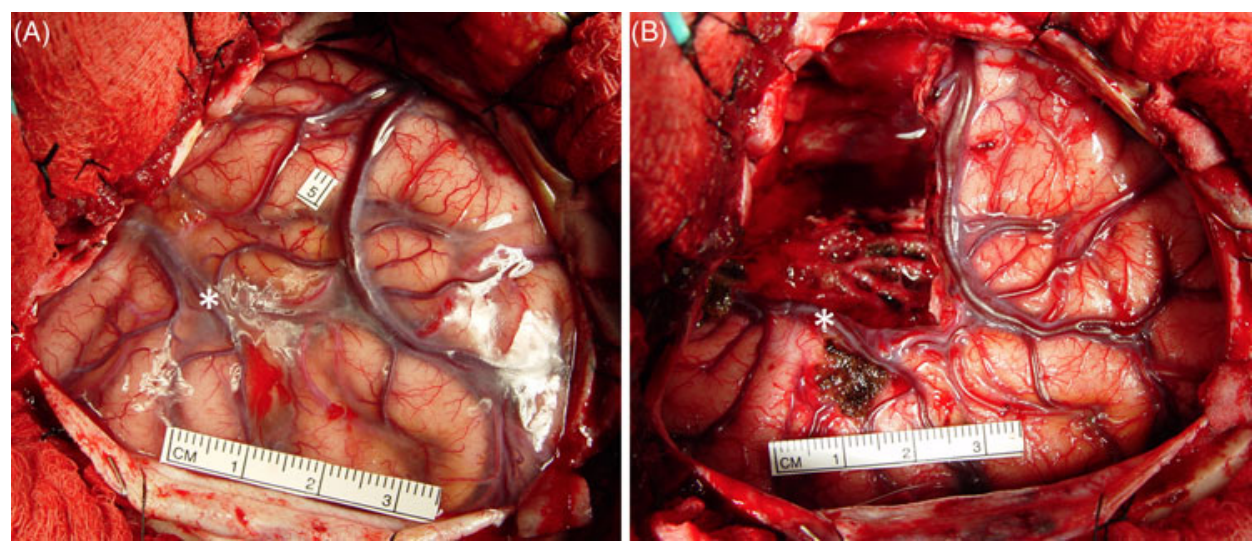

Figure 4. Intraoperative images of Case 2. (A) Right frontotemporal craniotomy before resection. The 5-cm mark shows the distance to the tip of temporal pole, just in front of a prominent vein of Labbé. * The surface of the sylvian fissure. (B) After resection. The right anterior temporal lobe has been removed. The inferior portion of the insula is exposed and a cortical resection between the MCA branches is shown.

patient was investigated with SEEG, and seven seizures with simultaneous onset in the right hippocampus and inferior insula were recorded (Figure 2). The patient was offered a right ATL with partial resection of the insular cortex. The latter was performed with the aid of neuronavigation, accessing the insula transpially and resecting the tissue that overlapped the active contacts of the depth electrodes involved (Figures 1B, 3A-J and 4A and B). Patient has remained seizure-free since surgery, 1.3 years ago.

Case 3: Twenty-seven-year-old, right-hand dominant male with seizure onset at the age of 14 years. He experienced focal unaware sensory seizures with gustatory auras, left-head version and dystonic posturing. Ictal spitting was frequently present and BTC seizures were common. Neuropsychological evaluation lateralized language to the left hemisphere and was otherwise normal. MRI showed no focal abnormality. PET scan showed hypometabolism of the right temporal lobe. VEEG lateralized seizures to the right hemisphere but was non-localizing. SEEG identified 12 seizures arising from the right hippocampus and simultaneously in the right anterior and posterior insular electrodes (Figure 5). The surgery was a right ATL with partial insulectomy (Figure 1C). Patient is seizure-free after 1.3 years of follow-up.

Case 4: Forty-year-old, right-hand dominant female with seizure onset when she was 9 months old. Semiologically, she experienced focal emotional seizures with impaired awareness. Seizures began with fear/anxiety and occasionally with paresthesias in both her feet. This would typically progress to slurred speech or vocalization, rightward head deviation, clonic jerking of the left arm, and progression to BTC seizures. Neuropsychology revealed left language dominance which was confirmed during Wada test, and bilateral temporal memory dysfunction. MRI 


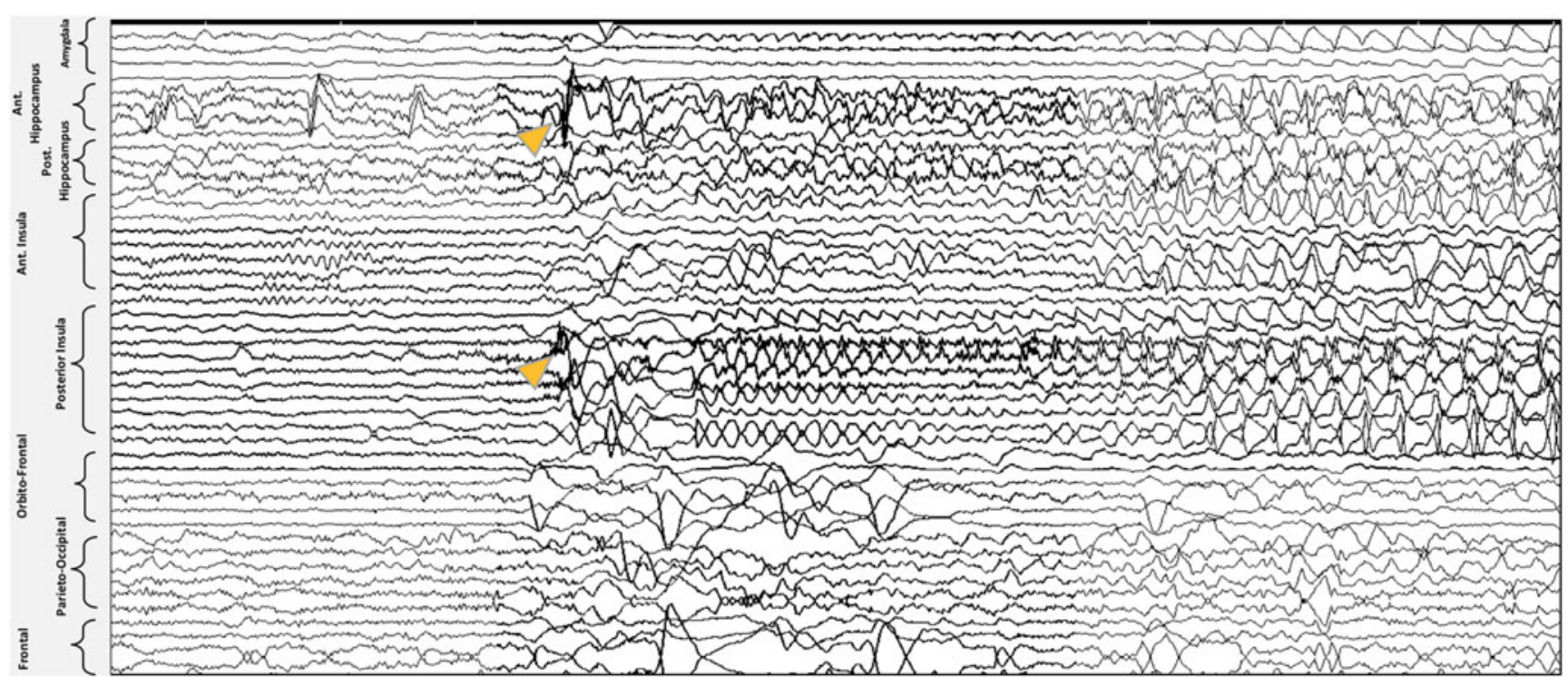

Figure 5: Case 3. Ictal Stereo-EEG (Referential montage): all the seizures recorded were electrographically stereotyped and preceding the clinical onset. Onset with high-amplitude spike over the right mesial temporal region and simultaneously with high-voltage spike over right posterior insula (shown by the yellow arrowheads). After that, there was a desynchronization for less than 2 , followed by low-voltage fast activity (LVFA) in the same electrodes. The LVFA activity progressively builds up in the right mesial temporal as well as the right anterior and posterior insula.

revealed bilateral hippocampal volume reduction. The scalp VEEG found left anterior temporal onset in all recorded seizures. The decision was made to proceed with invasive investigations using bilateral subdural strips, which revealed left-sided temporal lobe seizures. A left ATL was performed, which rendered her seizure-free for 3 years. After seizure recurrence, seizures seemed to have the same semiology. EEG showed mostly posterior left temporal seizures. A new invasive investigation with depth electrodes was suggested. The SEEG study revealed numerous spikes and electrographical seizures arising in the posterior hippocampus. Six clinical seizures were obtained with clear onset over the left anterior-inferior insula. Based on these findings, an additional anterior insulectomy was performed (Figure 1D). Despite having occasional auras, patient has remained seizure-free after 4.5 years following the procedure.

Case 5: Forty-six-year-old, left-hand dominant female with seizure onset at the age of 2 months. She had congenital hydrocephalus, which required shunting in the neonatal period. She experienced nocturnal progression to BTC and daytime focal unaware seizures with behavioral arrest and right-hand automatisms. Neuropsychology identified left language dominance and left frontal and neocortical dysfunction with memory preserved bilaterally. MRI showed moderately enlarged ventricles, but no focal abnormalities were found. Abundant right temporal spikes as well as right frontotemporal seizures were identified in scalp EEG. Five seizures were recorded during the SEEG study, four of them with onset in the right amygdala and hippocampus, and one seizure with clear onset in the right orbitofrontal cortex (posterior gyrus rectus and adjacent orbital gyrus). Unfortunately, during the fifth seizure, the electrodes were accidentally explanted. Despite this, sufficient information was obtained to recommend a right ATL with orbitofrontal corticectomy (Figure 1E). Patient is seizure-free at 1.3 years following the surgery.
Case 6: Forty-year-old, right-hand dominant female with seizure onset at the age of 27 years. A right-sided insular cavernoma was found and a resective surgery was undertaken initially. Seizures recurred within 3 months, mostly consisting of behavioral arrest, bimanual automatisms, and left arm jerking. Neuropsychology identified atypical language laterality and memory preserved bilaterally. MRI showed hemosiderosis in the right insula. Right frontotemporal spikes were identified in scalp EEG but no seizures were captured. She underwent invasive recording of the right frontotemporal region via subdural electrodes. Numerous seizures arose from the right mesial temporal region. An ATL with visual exploration of the insula was conducted; however, no tissue was resected in the latter structure. The patient was seizure-free for 3 years, after which the episodes recurred with the same semiology and became increasing in frequency after 5 years. Forty-seven seizures were recorded during the SEEG study, all arising from the right insula. A supplementary insular corticectomy was performed (Figure 1F) and the patient is free of disabling seizures at 4.7 years following the surgery (Engel 1c).

\section{Discussion}

The concept of TPE is not new, but literature is limited on the subject. A comprehensive concept was first approached by Ryvlin and Kahane to describe a subgroup of failed TLE surgery patients. ${ }^{6}$ This distinction from other causes of TLE surgery failure (hippocampal remnant, ${ }^{4}$ broader EZ, ${ }^{13}$ bilateral TLE, ${ }^{14}$ multilobar epilepsy, or dual pathology ${ }^{3}$ ) can certainly provide a new hope for these patients as some data suggest that further resection in specific cases may translate into good outcomes. ${ }^{6}$

The concept has evolved in recent years. ${ }^{1,15}$ Currently, TPE should be considered when patients have: (a) electroclinical features of TLE, (b) MTS findings on MRI or non-lesional MRI, and (c) intracranial investigations that show either 
seizure onset at two simultaneous foci or two different seizure foci (one temporal and one in adjacent extratemporal structures). ${ }^{1}$ These adjacent structures are richly connected with the temporal lobe and can be frequently involved in the epileptogenic network. ${ }^{16-18}$ Although some semiological associations with TPE have been found, ${ }^{19}$ distinction between pure TLE and TPE is usually difficult on the basis of noninvasive studies. The role of more complex noninvasive technologies such as magnetoencephalography or PET could be promising but further research is needed. ${ }^{20,21}$

According to Barba et al., TPE could account for one-third of the cases of failed ATLs. ${ }^{2,22}$ This was the case for two of the patients (Cases 4 and 6) presented in this series. Likely, more TPE patients will be identified as SEEG becomes more widely used and performed in patients with ATL who are not seizurefree. The identification of additional TPE cases among our pool of failed TLE surgery cases is limited due to the fact that SEEG has taken over as the preferred method for intracranial investigation at our center only recently, since $2013 .^{23}$ This means that more failed cases are currently under re-evaluation and are waiting for SEEG. Although subdural strips can identify some of the extratemporal foci in addition to the temporal focus, the insula would remain unsampled.

Indeed, the insula seems to play a major role in TPE. ${ }^{15,24,25}$ In the present series, this structure was involved in four of the six cases presented. Although there is an increased risk of generating postoperative deficits, ${ }^{26-29}$ resections in the insula are feasible and can be performed safely in experienced hands. The effort should not be avoided since it might improve postoperative outcomes, thus impacting patients' quality of life positively.

As a small case series, this study has limitations. TPE cases were identified retrospectively by reviewing a series of cases who underwent invasive studies (subdural strips/grids and SEEG) and had subsequent surgery. The fact that these cases were seizurefree does not mean that all TPE cases should follow the same outcome. Although the aim was not to provide substantial clinical evidence, our experience will likely contribute to the growing knowledge on TPE. As mentioned earlier, TPE diagnosis is limited to SEEG because subdural investigations cannot rule out insular or deep opercular involvement. Further analysis should focus on failed ATLs and reinvestigation with SEEG as it becomes more available in most epilepsy centers.

\section{Conclusion}

TPE is an evolving concept that can explain part of the failures in TLE surgery. We present a small case series of six patients in which SEEG successfully identified this phenomenon and was translated into postoperative seizure freedom.

\section{Disclosure}

The authors have no conflicts of interest to declare.

\section{STATEMENT OF AUTHORShIP}

Study design and concept (JSB \& ASM), data recollection, literature research creation/edit of figures, and manuscript drafting (JSB); creation of tables, final manuscript drafting (JSB \&ASM), SEEG clipping (ASM), manuscript review
(AGP, KWM, RSM, JGB, and DAS). Study supervision and final correction (DAS).

\section{Patient consent}

All subjects gave informed medical consent for procedures and for the academic use of surgical footage, medical records, clinical imaging, and other relevant data.

\section{ETHICAL ADHERENCE}

The study was approved by the institutional ethical review board.

\section{REFERENCES}

1. Kahane P, Barba C, Rheims S, Job-Chapron AS, Minotti L, Ryvlin P. The concept of temporal plusg epilepsy. Rev Neurol. 2015;171(3): 267-72.

2. Barba C, Rheims S, Minotti L, et al. Temporal plus epilepsy is a major determinant of temporal lobe surgery failures. Brain. 2015;139(2):444-51.

3. Li L, Cendes F, Watson C, et al. Surgical treatment of patients with single and dual pathology. Neurology. 1997;48:437-44.

4. Jobst BC. Temporal plus epilepsy: epileptic territory beyond the temporal lobes. Epilepsy Curr. 2016;16(5):305-07.

5. Andrade-Machado R, Benjumea-Cuartas V. Temporal plus epilepsy: anatomo-electroclinical subtypes. Iran J Neurol. 2016;15(3):153-63.

6. Ryvlin P, Kahane P. The hidden causes of surgery-resistant temporal lobe epilepsy: extratemporal or temporal plus? editorial review. Curr Opin Neurol. 2005;18(2):125-27.

7. Fisher RS, Cross JH, French JA, et al. Operational classification of seizure types by the international league against epilepsy: position paper of the ILAE commission for classification and terminology. Zeitschrift fur Epileptol. 2018;31(4):272-81.

8. Fisher RS, Cross JH, D'Souza C, et al. Instruction manual for the ILAE 2017 operational classification of seizure types. Zeitschrift fur Epileptol. 2018;31(4):282-95.

9. Girvin JP. Operative techniques in epilepsy surgery. New York, NY: Springer; 2015.

10. Steven DA, Andrade-Souza YM, Burneo JG, McLachlan RS, Parrent AG. Insertion of subdural strip electrodes for the investigation of temporal lobe epilepsy - technical note. J Neurosurg. 2007;106(6):1102-06.

11. Joswig H, Benson CM, Parrent AG, MacDougall KW, Steven DA. Operative nuances of stereotactic leksell frame-based depth electrode implantation. Oper Neurosurg. 2018;15(3):292-95.

12. Rheims S, Ryvlin P, Scherer C, et al. Analysis of clinical patterns and underlying epileptogenic zones of hypermotor seizures. Epilepsia. 2008;49(12):2030-40.

13. Salanova V, Markand O, Worth R. Temporal lobe epilepsy: analysis of failures and the role of reoperation. Acta Neurol Scand. 2005;111(2):126-33.

14. Aghakhani Y, Liu X, Jette N, Wiebe S. Epilepsy surgery in patients with bilateral temporal lobe seizures: a systematic review. Epilepsia. 2014;55(12):1892-901.

15. Barba C, Minotti L, Job AS, Kahane P. The insula in temporal plus epilepsy. J Clin Neurophysiol. 2017;34(4):324-27.

16. Tropeano MP, Santoro A, Delfini R, Manfreda A, Pescatori L. Threedimensional anatomy of the white matter fibers of the temporal lobe: surgical implications. World Neurosurg. 2017;100:144-58.

17. Enatsu R, Gonzalez-Martinez J, Bulacio J, et al. Connections of the limbic network: a corticocortical evoked potentials study. Cortex. 2015;62:20-33.

18. Karunakaran S, Rollo MJ, Kim K, et al. The interictal mesial temporal lobe epilepsy network. Epilepsia. 2018;59(1):244-58.

19. Barba C, Barbati G, Minotti L, Hoffmann D, Kahane P. Ictal clinical and scalp-EEG findings differentiating temporal lobe epilepsies from temporal "plus" epilepsies. Brain. 2007;130(7): 1957-67. 
20. Zhu H, Liu Y, Wu Y, et al. Temporal plus epilepsies: electrophysiology studied with interictal magnetoencephalography and intracranial video-EEG monitoring. Seizure. 2013;22(2):164-67.

21. Chassoux F, Artiges E, Semah F, et al. 18 F-FDG-PET patterns of surgical success and failure in mesial temporal lobe epilepsy. Neurology. 2017;88(11):1045-53.

22. Engel J. When is temporal lobe epilepsy not temporal lobe epilepsy? Brain. 2016;139(2):306-09.

23. Joswig H, Steven DA, Parrent AG, et al. Intracranial electroencephalographic monitoring: from subdural to depth electrodes. Can J Neurol Sci. 2018;45(3):336-38.

24. Isnard J, Guénot M, Ostrowsky K, Sindou M, Mauguière F. The role of the insular cortex in lobe epilepsy. Ann Neurol. 2000; 48(4): 614-23.
25. Ghaziri J, Tucholka A, Girard G, et al. The corticocortical structural connectivity of the human insula. Cereb Cortex. 2017;27(2): 1216-28.

26. Bouthillier A, Nguyen DK. Epilepsy surgeries requiring an operculoinsular cortectomy: operative technique and results. Clin Neurosurg. 2017;81(4):602-11.

27. Laoprasert P, Ojemann JG, Handler MH. Insular epilepsy surgery. Epilepsia. 2017;58:35-45.

28. Finet P, Nguyen DK, Bouthillier A. Vascular consequences of operculoinsular corticectomy for refractory epilepsy. J Neurosurg. 2015;122(June):1293-298.

29. von Lehe M, Parpaley Y. Insular cortex surgery for the treatment of refractory epilepsy. J Clin Neurophysiol. 2017;34(4): 333-39. 